Review

\title{
Myeloid-Derived Suppressor Cells Interact with Tumors in Terms of Myelopoiesis, Tumorigenesis and Immunosuppression: Thick as Thieves
}

\author{
Alexandra Sevko, Viktor Umansky ${ }^{凶}$ \\ Skin Cancer Unit, German Cancer Research Center, Heidelberg and Department of Dermatology, Venereology and Allergology, University \\ Medical Center Mannheim, Ruprecht-Karl University of Heidelberg, Mannheim, 69120 Heidelberg, Germany.

\begin{abstract}
$\square$ Corresponding author: Viktor Umansky, Skin Cancer Unit, German Cancer Research Center, Heidelberg and Department of Dermatology, Venereology and Allergology, University Medical Center Mannheim, Ruprecht-Karl University of Heidelberg, Mannheim, 69120 Heidelberg, Germany. Phone: 49-621-383-3773; Fax: 49-621-383-2163; E-mail: v.umansky@dkfz.de.
\end{abstract} \\ (C) Ivyspring International Publisher. This is an open-access article distributed under the terms of the Creative Commons License (http://creativecommons.org/ \\ licenses/by-nc-nd/3.0/). Reproduction is permitted for personal, noncommercial use, provided that the article is in whole, unmodified, and properly cited.
}

Received: 2012.10.19; Accepted: 2012.11.20; Published: 2012.11.30

\begin{abstract}
Tumor progression is often associated with chronic inflammation in the tumor microenvironment, which is mediated by numerous cytokines, chemokines and growth factors produced by cancer and stroma cells. All these mediators support tumor development and immunosuppression in autocrine and/or paracrine ways. Neutralization of chronic inflammatory conditions can lead to the restoration of anti-tumor immune responses. Among stroma cells infiltrating tumors, myeloid-derived suppressor cells (MDSCs) represent one of the most important players mediating immunosuppression. These cells may not only inhibit an anti-tumor immunity but also directly stimulate tumorigenesis as well as tumor growth and expansion. Therefore, understanding the mechanisms of generation, migration to the tumor site and activation of MDSC is necessary for the development of new strategies of tumor immunotherapy.
\end{abstract}

Key words: myeloid-derived suppressor cells, cancer, myeloipoiesis, tumorigenesis, immunosuppression.

\section{Introduction}

MDSCs are immature myeloid cells that fail to terminally differentiate into granulocytes, macrophages or dendritic cells (DCs) upon chronic inflammatory conditions and exhibit immunosuppressive functions by multiple mechanisms (1-4). These cells are very heterogeneous and therefore their phenotypical characteristics are broadly distinct (1, 4-6). In mice, MDSCs express both CD11b and Gr1 markers and consist of two major subsets: granulocytic Ly6G ${ }^{+}$Ly6Clo and monocytic Ly6G-Ly6Chi cells (1, 5, 8). Among human MDSCs, the same two subsets can be distinguished as Lin-HLA-DR-CD33 ${ }^{+}$or

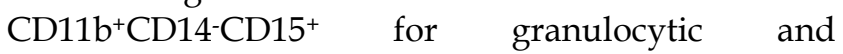

CD14 ${ }^{+}$HLA-DR ${ }^{\text {neg }} /$ lo $\quad$ or $\quad$ CD $11 b^{+}$CD $14^{+} H_{L A}-D R^{\text {neg }} /$ lo for monocytic MDSCs $(1,2,6,8)$. MDSCs derive from the bone marrow hematopoietic precursors due to the altering of myelopoiesis by chronic inflammatory mediators $(1,9,10,12)$ and exhibit remarkable immunosuppressive and tumorigenic activities $(1,6,13)$. The later include i) a secretion of angiogenic factors promoting neoangiogenesis (14); ii) a production of growth factors, matrix metalloproteinases and cytokines stimulating tumor growth and skewing immune responses towards Th2 type and regulatory $\mathrm{T}$ cells (Tregs) $(13,15,16)$; iii) a deprivation of arginine and cysteine which are required for $\mathrm{T}$ cell functions $(1,17)$; 
iv) a production of nitric oxide (NO) and reactive oxygen species (ROS) that causes the nitration of $\mathrm{T}$ cell receptors (TCR) or T cell apoptosis $(1,13,18)$; v) an expression of membrane-bound TGF- $\beta 1$ inducing anergy of immune effector cells $(1,19)$, and vi) a down-regulation of the TCR $\zeta$-chain expression disabling $\mathrm{T}$ cells to transmit activation signals $(1,9)$. Taking together, MDSCs can be considered as key players in the tumor-mediated immunosuppression. In this review, we will summarize a current knowledge on the MDSCs-tumor interplay and will discuss the checkpoints of this interaction to be used as possible therapeutic targets.

\section{Tumor-derived factors supporting MDSCs generation, expansion and func- tion}

Previously we and others demonstrated a strong association of the tumor-mediated chronic inflammation and systemic expansion and activation of MDSCs $(1,9,20)$. Neutralization of chronic inflammatory conditions led to a strong decrease in numbers and immunosuppressive functions of tumor-infiltrating MDSCs (20-22). In contrast, a cyclophosphamide-induced escalation of chronic inflammation caused an additional expansion, activation and accumulation of MDSCs in tumor lesions (Sevko et al., accepted to JID, 2012; 23). The process of MDSC generation, expansion, migration and activation is known to be under the control of various mediators of chronic inflammation such as growth factors (granulocyte-macrophage colony-stimulating factor, GM-CSF; granulocyte colony-stimulating factor, G-CSF; macrophage colony-stimulating factor, M-CSF; vascular endothelial growth factor (VEGF); and transforming growth factor- $\beta$, TGF- $\beta$ ), cytokines (interleukin (IL)-1 $\beta$, IL-4, IL-5, IL-6, IL-10, IL-13; tumor necrosis factor- $\alpha$, TNF- $\alpha$; and interferon- $\gamma$, IFN- $\gamma$ ), chemokines (CCL2, CCL4, CCL5, CXCL1, CXCL8, and CXCL12), cyclooxygenase-2 (COX-2), and prostaglandin E2 (PGE2) $(1,3,9,24,25)$. The effect of all these factors is combinatorial and dose-dependent (Fig. 1). They modulate myeloid cells in the tumor microenvironment, and being delivered distantly to hematopoietic organs by tumor-derived exosomes, can alter myelopoiesis and skew a normal differentiation of myeloid cells in the favor of MDSCs $(1,3,7,25$, 26).

GM-CSF is considered as a pivotal growth factor driving myelopoiesis $(27,28)$. Further differentiation to granulocytes or macrophages is stimulated by G-CSF or M-CSF respectively) (29). All three mentioned growth factors have been shown to be ex- pressed in tumor lesions $(10,30,31)$. Tumor-derived GM-CSF has been reported to be one of the key factors in the generation of MDSC both in vivo $(32,33)$ and in vitro (34). Moreover, Ribechini E et al (35) emphasized a dose-dependent effect of GM-CSF. Whereas low concentrations of GM-CSF in absence of IL-4 led to the generation of MDSCs and immature DCs from bone marrow hematopoietic precursor cells in vitro, high doses resulted in the development of neutrophiles and mature DCs. Finally, GM-CSF in combination with IL-6, IL-1 $\beta$, PGE2, TNF- $\alpha$ or vascular VEGF has been demonstrated to mediate the generation of highly suppressive MDSCs from $\mathrm{CD}^{2} 3^{+}$peripheral blood mononuclear cells (PBMCs) isolated from healthy donors (36).

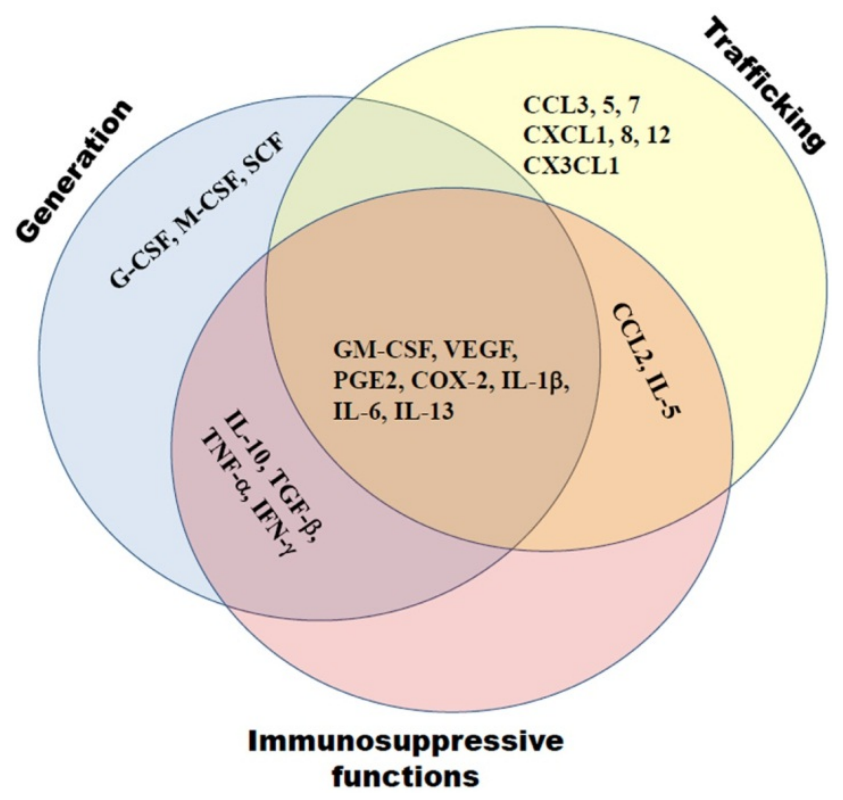

Figure I. Tumor-derived mediators of chronic inflammation affect MDSC generation, trafficking towards tumors and support the MDSC immunosuppressive activity. These molecules include growth factors (GM-CSF, G-CSF, M-CSF, VEGF, TGF- $\beta$ ), cytokines (IL-I $\beta$, IL-4, IL-5, IL-6, IL-I0, IL-13, TNF- $\alpha$, IFN- $\gamma$ ), chemokines (CCL2, CCL4, CCL5, CXCLI, CXCL8, CXCLI2), COX-2 and PGE2. Their effects are often complementary.

VEGF and TGF- $\beta$ were also found to be involved in the regulation of hematopoiesis (37-39). Both factors are produced in high amounts by many tumors and have a strong impact on the MDSC generation and expansion $(1,9,10)$. Thus, it was documented that tumor-derived VEGF interfered with the proliferation, differentiation and maturation of immature granulocyte-macrophage progenitors, causing a block of DC maturation and activation as well as a development of immunosuppressive tumor-associated macrophages (TAMs); the recruitment of macro- 
phages into the tumor was also associated with the VEGF activity (40, 41). Synergizing with VEGF, TGF- $\beta$ prevented maturation of DCs, polarized myeloid cells towards immune suppressive cells in the tumor microenvironment and participated in the TAM formation $(42,43)$.

Impairment of normal myelopoiesis could be also induced by the changes in various cytokines and chemokines $(44,45)$. These factors are commonly present in the tumor microenvironment and are orchestrating by IL-1 $\beta$ (46). Thus, IL-1 $\beta$ production at the tumor site is known to be involved in the MDSC generation in the bone marrow $(47,48)$ and in their migration towards tumor lesions (49). Moreover, IL-1 $\beta$ can induce COX-2 expression (50) that together with PGE2 is able to prevent the maturation and immune functions of antigen-presenting cells at the tumor site, mediating thereby an accumulation of MDSCs and TAMs and promoting tumor progression $(51,52)$. IL-1 $\beta$ was reported to up-regulate TNF- $\alpha$ levels in the tumor microenvironment, inducing its production by myeloid and/or tumor cells (53-55). Together with IL-1 $\beta$ and TNF- $\alpha$, IFN- $\gamma$ was also shown to be enriched in many tumors, leading to a continuous activation of myeloid cells and an enhancement of chronic inflammation in situ $(9,56,57)$. In particular, all these factors are known to stimulate the production of NO that mediate an MDSC immunosuppressive activity $(48,58)$. In addition, IL- $1 \beta$ was reported to stimulate the IL-10 production by MDSC and to be associated with elevated levels of IL- 5 and IL-13 (48), which induced a type 2 immune reactions and attracted MDSCs to the tumor site (59-61). IL-6 was also demonstrated to be strongly associated with chronic inflammation and cancer $(62,63)$. Elevated IL-6 levels were reported to correlate with MDSC frequencies and their suppressive functions in tumor-bearing hosts $(20,64-66)$. It has been reported that IL-6 mediated generation, migration and activity of MDSCs via signal transducer and activator of transcription 3 (STAT3) transcription factor $(3,13$, 67-69). In mice, inhibition of IL-6 or IL-6R resulted in the prominent reduction of MDSCs infiltrating tumors and in the inhibition of tumor growth $(65,70)$.

The chemokine patterns involved in MDSC migration into the tumor seem to be dependent on the MDSC subset and on the tumor model. The role of chemokine (C-C motif) ligand (CCL) 2 and its receptors in the attraction of monocytic MDSCs has been documented. It has been demonstrated by us (unpublished observations) and others (71-74) that an accumulation of monocytic MDSCs in melanoma and prostate cancer occurred via an interaction between CCL2 and its receptors, chemokine (C-C motif) re- ceptor (CCR) 2, 4, and 5. Moreover, melanoma-infiltrating monocytic MDSCs exhibited CCR2-dependent immunosuppressive activities under the chronic GM-CSF production (71). The PGE2-driven production of CCL2, C-X-C chemokine ligand (CXCL) 8 (also known as IL-8), and CXCL12, led to the MDSC accumulation in ovarian and gastric cancer environment (75-77). On the contrary, the expression of the wild-type CXCL12 was reported to reduce MDSC accumulation in a syngeneic model of breast cancer (78). Other groups underlined a dominating role of CCL3, CCL5 and CX3CL1 but not CCL2 in the monocytic MDSC migration (79) or an importance of CXCL-1 (also known as KC), CCL5 and CCL7 in the MDSC enrichment in colon and liver carcinomas $(80,81)$. Moreover, using various transplantable tumor mouse models, Sawanobori et al (82) demonstrated that MDSC migration into the tumor was mediated by different chemokines. Whereas CCR2/CCL2 axis was important for the accumulation of monocytic MDSCs, the enhanced production of CXCR2 ligands in tumors supported the migration of the granulocytic subset. Therefore, the migration of different MDSC subsets in to the tumor site can be strongly determined by the histology and the spectrum of chemokines produced by particular tumors.

\section{MDSCs support tumorigenesis and tumor progression}

There are growing evidences that MDSCs and chronic inflammation are participating in tumorigenesis (Fig. 2), which became possible with the establishment of transgenic mouse models with a spontaneous tumor development. Using a ret transgenic mouse model of spontaneous melanoma, we have demonstrated a systemic elevation of MDSC numbers in transgenic mice without macroscopic skin tumors as compared to non-transgenic littermates (20). Human ret transgene is expressed in melanin containing cells of mice that spontaneously develop malignant skin melanoma with metastases in lymph nodes, lungs, liver, brain, and bone marrow. Furthermore, an accumulation of highly suppressive MDSCs in melanoma lesions was demonstrated to be highly associated with the rate of tumor progression (20). Using transgenic mouse model of lung cancer, Qu et al (16, 83) demonstrated that the constant induction of apoptosis inhibitor 6 (Api6/AIM/Sp alpha) or matrix metalloproteinase 12 (MMP12) in myeloid cells led to a systemic increase in numbers of MDSCs, DCs, neutrophiles and macrophages associated with a severe inflammation and a massive tissue remodeling in lungs; this resulted in the lung adenocarcinoma development in $35 \%$ of animals. 


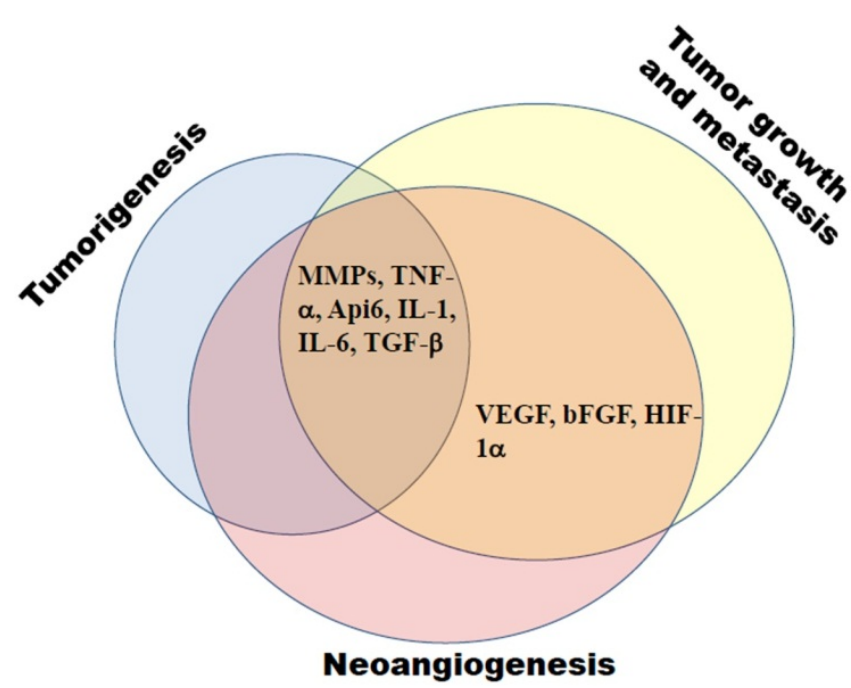

Figure 2. MDSCs create favorable conditions for tumorigenesis, tumor growth and metastasis, and neoangiogenesis. These processes are tightly related and are governed by MDSC-derived mediators, such as matrix metalloproteinases (MMPs), apoptotic factors (TNF- $\alpha$, Api6), interleukins (IL-I, IL-6), growth factors (TGF- $\beta$, VEGF, bFGF), and hypoxia-induced factor (HIF)- I $\alpha$.

It has been recently reported that Pten deletion in the mouse head and neck epithelia resulted in a constant activation of the PI3K/Akt pathway and caused a development of benign epithelial hyperplasia (84). When the Pten deletion was coincided with the deletion of type I TGF- $\beta$ receptor, mice developed head and neck squamous cell carcinoma (HNSCC) associated with the tumor infiltration by MDSCs, enhanced angiogenesis and immune suppression in the tumor microenvironment (84). Furthermore, $\mathrm{Wu} \mathrm{L}$ et al (12) demonstrated that abruptions of the LAL/hormonal ligand/PPAR pathway in myeloid cells caused a skewing of hematopoietic progenitors toward the myeloid-lineage expansion and MDSC formation followed by the development of chronic inflammation indicated by the up-regulation of inflammatory molecules such as Api 6, MMP12, IL-1, IL-6, and TNF- $\alpha$ (12). Such MDSC expansion and chronic inflammation caused an inhibition of T-cell functions, creating an environment for the development of spontaneous carcinomas and sarcomas (12).

MDSCs have been also demonstrated to support neoangiogenesis, tumor growth and metastasis (Fig. 2) $(1,9,25,85)$. These cells are known to produce VEGF, basic fibroblast growth factor (bFGF), hypoxia-induced factor (HIF)-1, TGF- $\beta$, and MMP9 that promote neoangiogenesis and create a pre-metastatic environment $(14,85,86)$. Moreover, produced by
MDSCs S100A8/A9 inflammatory proteins have been reported not only to attract MDSCs into the tumor site and enhance their immunosuppressive activity but also to promote the activation of MAPK and NF- $\mathrm{kB}$ signaling pathways in tumor cells, stimulating thereby the tumor growth and metastasis (81, 87-89). In addition, MDSCs are able to strongly promote tumor progression by inhibiting anti-tumor immune responses by multiple mechanisms which are thoroughly discussed in previous reviews $(1,13,17,47$, 90). Therefore, the neutralization of MDSC-induced immunosuppression represents an important strategy for the development of more efficient tumor immunotherapies.

\section{Overcoming MDSC-mediated immuno- suppression}

Down-regulation of MDSC frequencies and/or abrogation of their immunosuppressive functions have been reported to delay the tumor growth and to prolong the survival both in animal models and in cancer patients $(6,11,91,92)$. These could be achieved by means of three major approaches: i) regulation of myelopoiesis; ii) MDSC depletion by the elimination or prohibiting their trafficking towards tumors; and iii) inhibition of MDSC immunosuppressive activities (Fig. 3).

Regulation of myelopoiesis includes the prevention of MDSC generation from bone marrow precursor cells and the stimulation of further MDSC differentiation towards mature DCs and macrophages. One of main targets in the circumvention of MDSC formation is stem cell factor (SCF) (93-97). The knockdown of SCF with siRNA and blockage of SCF signaling by anti-c-kit antibodies or with tyrosine kinase inhibitors such as sunitinib, pazopanib and sorafenib have been found to significantly reduce MDSC numbers in the human bone marrow precursors in vitro as well as in murine models of colon carcinoma and Lewis lung carcinoma associated with enhanced tumor-specific immune responses, tumor regression and significantly prolonged survival. In addition, sunitinib has been reported to reverse the MDSC accumulation in patients with renal cell carcinoma (RCC) resulting in the restoration of Th1 cells and a decrease of regulatory $\mathrm{T}$ cells (96). This beneficial effect of sunitinib effect was also detected in the murine RCC model correlated with the inhibition of immunosuppressive functions of pre-existing tumor-derived MDSC subsets $(97,98)$. 


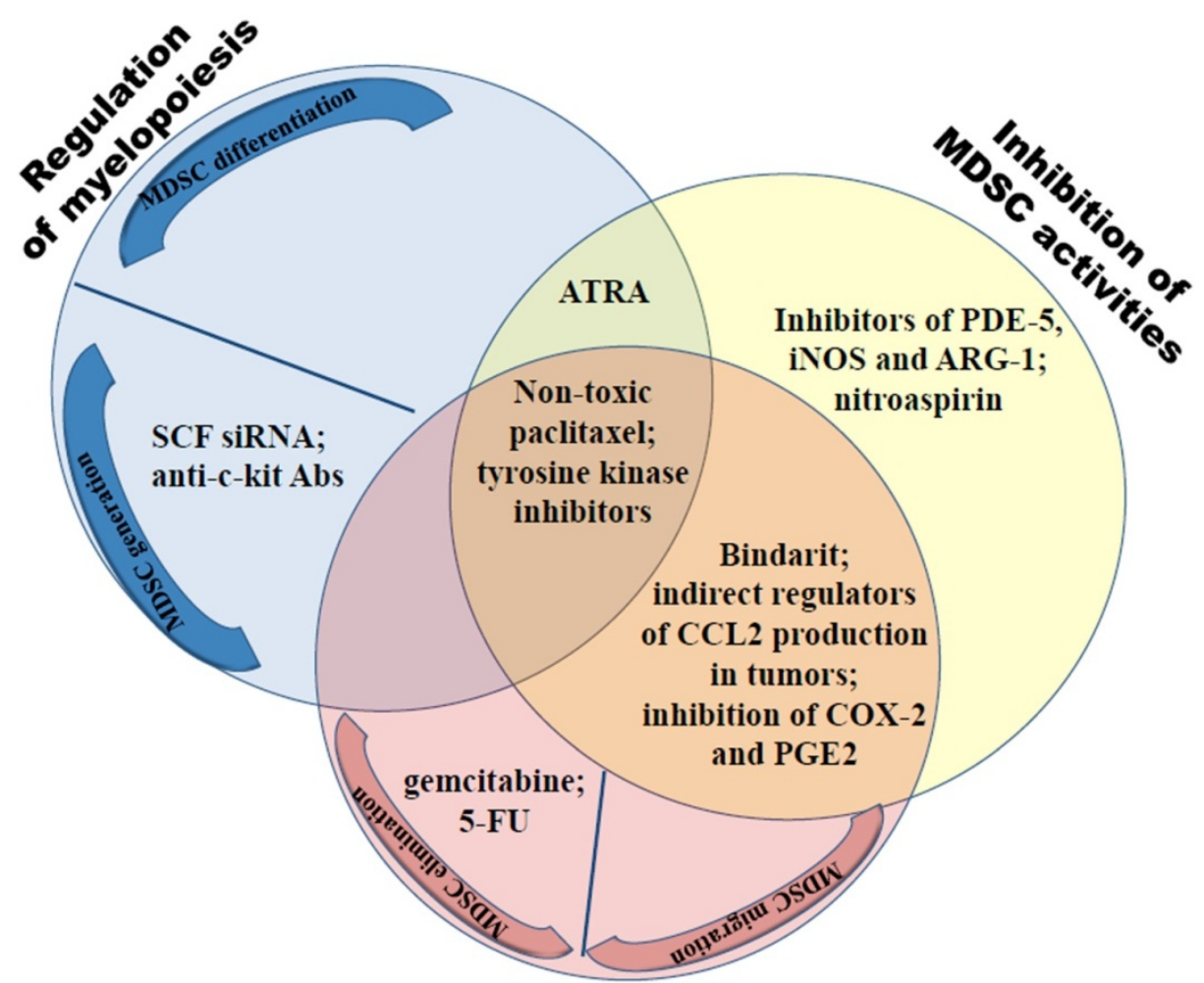

Depletion of MDSCs

Figure 3 Neutralization of the MDSC-mediated immunosuppression includes the regulation of myelopoiesis, the MDSC depletion and inhibition of their activities. Myelopoiesis can be regulated either by preventing MDSC generation via the inhibition of c-kit or tyrosine kinase signaling or through the induction MDSC terminal differentiation using all-trans-retinoic acid (ATRA) or ultra-low doses of paclitaxel. Depletion of MDSCs can be achieved either by gemcitabine or 5-fluorouracil (5-FU) or by the abrogation of CCL2-, CXCL-8 and CXCLI2-mediated MDSC trafficking towards tumors. CCL2 can be affected either directly by bindarit or indirectly by regulators of the CCL2 production in tumors. Inhibitors of COX-2 and PGE2 prevent CCL2, CXCL8 and CXCL12 production in tumors targeting thereby the migration of granulocytic and monocytic MDSCs. Immunosuppressive functions of MDSCs can be blocked by inhibitors of PDE-5, iNOS and/or ARG-I as well as by nitroaspirin.

Regarding the stimulation of MDSC differentiation into mature macrophages, DCs or terminally differentiated granulocytes, two approaches have been reported so far dealing with the administration of all-trans-retinoic acid (ATRA) $(99,100)$ and ultra-low non-cytotoxic doses of paclitaxel (101). Retinoic acid receptors (RARs and RXRs) are present on numerous cell types, however, RAR $\alpha$ and $R X R \alpha$ are expressed predominantly on myeloid cells $(102,103)$. Whereas the combination of RA with G-CSF is known to drive the terminal granulocyte differentiation, RA together with vitamin D induced monocytic development from the normal hematopoietic precursor cells (102). First report on ATRA effects on MDSCs in patients with metastatic RCC was published in 2006 by Mirza et al (99). The combination of ATRA with IL-2 administration led to a profound reduction in MDSC numbers in the peripheral blood, an improved ratio between myeloid and lymphoid DCs, to an improvement of DC functions, and tumor-specific T-cell reactivity (99). Another group demonstrated that ATRA administration into tumor-bearing mice together with HPV therapeutic vaccination decreased MDSC numbers and immunosuppressive function of CD80 dim MDSC subset in the murine HPV-tumor model (100). Moreover, these impairments in MDSCs were associated with the restoration of functionally active E7-specific $\mathrm{T}$ cells and significant anti-tumor effects (100).

We demonstrated that the administration of chemotherapeutic paclitaxel at ultra-low non-toxic doses, designated as chemoimmunomodulation (104), into C57BL/ 6 mice significantly reduced the amount of $\mathrm{CD} 11 \mathrm{~b}^{+} \mathrm{Gr} 1^{+}$immature myeloid cells (known as a counterpart of MDSCs in normal mice) (105). This resulted in the augmentation of natural killer (NK) cell numbers in the bone marrow and their ability to produce IFN- $\gamma$. Moreover, paclitaxel chemoimmunomodulation enhanced the efficiency of vaccination with the peptide derived from tyrosinase related 
protein (TRP)-2, a model melanoma-associated antigen (105). Applying paclitaxel chemoimmunomodulation in tumor-bearing ret transgenic mice, we demonstrated a significant reduction in MDSC numbers and their functions and in the production of chronic inflammatory factors in melanoma lesions associated with a partial recovery of tumor-specific $\mathrm{T}$ cell responses, leading to profound anti-melanoma effects indicated by a delayed tumor growth and prolonged survival (Sevko et al, submitted). To highlight the mechanisms of MDSC reduction under ultra-low dose paclitaxel therapy, MDSCs were generated in vitro and treated with nanomolar concentrations of paclitaxel (101). MDSC differentiation towards DCs was found to be significantly stimulated in TLR4-independent way (101). In contrast, neither MDSC apoptosis nor MDSC generation from the bone marrow precursor cells were changed upon the paclitaxel treatment.

Direct selective elimination of MDSCs can be achieved by the administration of gemcitabine (106, 107) or 5-fluorouracil (108). Using several cancer models, it has been found that these chemotherapeutical agents depleted MDSCs without toxic effects on other leukocyte subsets, resulting in the markedly enhanced anti-tumor efficacy. The prevention of MDSC trafficking towards tumor lesions is based on the targeting of tumor-derived chemokines. Prostate and breast carcinomas, melanomas, colorectal cancer and Lewis lung carcinoma were found to produce various ligands for CCR2 (including CCL2), which were described to attract MDSC and to maintains their suppressive activity $(74,109-111)$. Direct CCL2 targeting with bindarit (74) or the inhibition of CCL2 production in tumors $(110,111)$ led to the decrease in MDSC amounts in tumors, reduction of metastasis and neoangiogenesis as well as in the delay in the growth of transplantable tumors $(74,110,111)$.

Neutralization of the MDSC-mediated immunosuppression could be also achieved by an inhibition of their immunosuppressive activity. Once attracted to the tumor microenvironment, MDSCs may affect anti-tumor immune responses by multiple mechanisms $(1,4,13,17)$. Major immunosuppressive activities of MDSCs were reported to be linked to the NO production and activation of arginase (ARG)-1. NO was shown i) to induce a nitration of $\mathrm{T}$ cell receptors in situ (90), ii) to target distinct signaling pathways resulting in the inhibition of cytokine production which are required for anti-tumor $\mathrm{T}$ cell reactivity, iii) and to mediate $\mathrm{T}$ cell apoptosis $(18,112)$. The activation ARG-1 induced a deprivation of L-arginine, which is essential for the protein synthesis by $\mathrm{T}$ lymphocytes (113). Importantly, the blockade of the ac- tivity of phosphodiesterase (PDE)-5 reported to increase intracellular concentrations of cyclic guanosine monophosphate (cGMP) resulting in the inhibition of both iNOS and ARG-1 activities (114). Based on these observations, PDE-5 inhibitors such as sildenafil, tadalafil and vardenafil have been recently proposed for the inhibition of MDSC immunosuppressive functions $(15,115,116)$. It has been shown by us on the ret transgenic melanoma model (20) and by Serafini et al on the transplantable models of adenocarcinoma and fibrosarcoma (116) that the chronic sildenafil administration with the drinking water caused a significant reduction in the production of NO production and in the expression of ARG-1. Furthermore, such inhibition of the MDSC-mediated immunosuppression could partially restore tumor-specific CD8 T cell responses. A similar effect was shown upon the treatment of MDSCs from the peripheral blood of multiple myeloma and head and neck cancer patients with sildenafil in vitro (116). Stimulation of CD8 T cell-mediated immune reactions by sildenafil in vivo resulted in the delay of tumor growth associated with a significantly prolonged survival of tumor-bearing animals $(20,116)$. Moreover, we were able to demonstrate that sildenafil strongly diminished chronic inflammation in the metastatic $\mathrm{LN}$ indicated by a drastic reduction of IL-1 $\beta$, VEGF, GM-CSF, CCL2, CCL3 and S100A9 production (20). In addition, the level of IL-6 in primary skin tumors was found to be decreased (20).

Besides PDE-5 inhibitors, the activity of iNOS and ARG-1 was found to be blocked by corresponding inhibitors $(115,117,118)$ or by nitroaspirin (119) leading to a significant $\mathrm{T}$ cell stimulation and anti-tumor effects. Interestingly, some agents that prevented MDSC migration towards tumors could also inhibit MDSC immunosuppressive functions. In particular, the inhibition of COX-2 activity and PGE2 production has been reported to reduce the CXCR4/CXCL12 and CXCR1-CXCR2/CXCL8 mediated MDSC trafficking $(75,76)$ and to impair the MDSC-mediated immunosuppression by reducing the production of ROS and NO production $(120,121)$ or the expression of ARG-1 in these cells (121).

\section{Conclusion}

The role of MDSCs in the tumorigenesis and tumor progression is clearly elucidated. Established tumors are able to produce multiple factors that impair the myelopoiesis favoring the MDSC formation, trafficking to the tumor site and their activation. MDSCs and tumors are thick as thieves depending on and supporting each other in all aspects. It is quite clear that the efficiency of different immunotherapeu- 
tic approaches will be strikingly dependent on the neutralization of MDSC-induced immunosuppression. Even adoptively transferred functionally active tumor-specific CD8 T cells either will develop anergy or even undergo apoptosis being migrated into in the tumor microenvironment. Therefore, understanding the mechanisms and checkpoint regulators of MDSC-tumor interaction is critically important to overcome immunosuppression mediated both by MDSCs and tumor cells to achieve better therapeutic effects in cancer patients.

\section{Conflict of Interest}

The authors have declared that no conflict of interest exists.

\section{References}

1. Ostrand-Rosenberg S, Sinha P. Myeloid-derived suppressor cells: linking inflammation and cancer. J Immunol. 2009; 182: 4499-506.

2. Youn JI, Gabrilovich DI. The biology of myeloid-derived suppressor cells: the blessing and the curse of morphological and functional heterogeneity. Eur J Immunol. 2010; 40: 2969-75.

3. Condamine T, Gabrilovich DI. Molecular mechanisms regulating myeloid-derived suppressor cell differentiation and function. Trends Immunol. 2011; 32:19-25.

4. Chioda M, Peranzoni E, Desantis G, et al. Myeloid cell diversification and complexity: an old concept with new turns in oncology. Cancer Metastasis Rev. 2011; 30: 27-43.

5. Youn JI, Nagaraj S, Collazo M, Gabrilovich DI. Subsets of myeloid-derived suppressor cells in tumor-bearing mice. J Immunol. 2008; 181: 5791-802.

6. Filipazzi P, Huber V, Rivoltini L. Phenotype, function and clinical implications of myeloid-derived suppressor cells in cancer patients. Cancer Immunol Immunother. 2012; 61: 255-63.

7. Filipazzi P, Bürdek M, Villa A, Rivoltini L, Huber V. Recent advances on the role of tumor exosomes in immunosuppression and disease progression. Semin Cancer Biol. 2012; 22: 342-9.

8. Peranzoni E, Zilio S, Marigo I, et al. Myeloid-derived suppressor cell heterogeneity and subset definition. Curr Opin Immunol. 2010; 22: 238-44.

9. Banyash M. Chronic inflammation, immunosuppression and cancer: new insights and outlook. Semin Cancer Biol. 2006; 16:80-8.

10. Wilcox R. Cancer-associated myeloproliferation: old association, new therapeutic target. Mayo Clin Proc. 2010; 85: 656-63.

11. Wilcox R. Myeloid-derived suppressor cells: therapeutic modulation in cancer. Front Biosci (Elite Ed). 2012; 188: 838-55.

12. Wu L, Yan C, Czader M, et al. Inhibition of PPARy in myeloid-lineage cells induces systemic inflammation, immunosuppression, and tumorigenesis. Blood. 2012; 119: 115-26.

13. Gabrilovich DI, Nagaraj S. Myeloid-derived suppressor cells as regulators of the immune system. Nat Rev Immunol. 2009; 9: 162-74.

14. Tartour E, Pere H, Maillere B, et al. Angiogenesis and immunity: a bidirectional link potentially relevant for the monitoring of antiangiogenic therapy and the development of novel therapeutic combination with immunotherapy. Cancer Metastasis Rev. 2011; 30: 83-95.

15. Serafini P, Mgebroff S, Noonan K, Borrello I. Myeloid-derived suppressor cells promote cross-tolerance in B-cell lymphoma by expanding regulatory T cells. Cancer Res. 2008; 68: 5439-49.

16. Qu P, Yan C, Du H. Matrix metalloproteinase 12 overexpression in myeloid lineage cells plays a key role in modulating myelopoiesis, immune suppression, and lung tumorigenesis. Blood. 2011; 117: 4476-89.

17. Ostrand-Rosenberg S. Myeloid-derived suppressor cells: more mechanisms for inhibiting antitumor immunity. Cancer Immunol Immunother. 2010; 59: 1593-600.

18. Bogdan C. Nitric oxide and the immune response. Nat Immunol. 2001; 2: 907-16.

19. Li H, Han Y, Guo Q, Zhang M, Cao X. Cancer-expanded myeloid-derived suppressor cells induce anergy of NK cells through membrane-bound TGF-beta 1. J Immunol. 2009; 182: 240-9.
20. Meyer C, Sevko A, Ramacher M, et al. Chronic inflammation promotes myeloid-derived suppressor cell activation blocking antitumor immunity in transgenic mouse melanoma model. Proc Natl Acad Sci U S A. 2011; 108: 17111-6.

21. Bunt SK, Yang L, Sinha P, Clements VK, Leips J, Ostrand-Rosenberg S. Reduced inflammation in the tumor microenvironment delays the accumulation of myeloid-derived suppressor cells and limits tumor progression. Cancer Res. 2007; 67: 10019-26.

22. Haverkamp JM, Crist SA, Elzey BD, Cimen C, Ratliff TL. In vivo suppressive function of myeloid-derived suppressor cells is limited to the inflammatory site. Eur J Immunol. 2011; 41: 749-59.

23. Mikyšková R, Indrová $M$, Polláková V, Bieblová J, Símová J, Reiniš M. Cyclophosphamide-induced Myeloid-derived Suppressor Cell Population Is Immunosuppressive But Not Identical to Myeloid-derived Suppressor Cells Induced By Growing TC-1 Tumors. J Immunother. 2012; 35: 374-84.

24. Chornoguz O, Grmai L, Sinha P, Artemenko KA, Zubarev RA, Ostrand-Rosenberg S. Proteomic pathway analysis reveals inflammation increases myeloid-derived suppressor cell resistance to apoptosis. Mol Cell Proteomics. 2011; 10: M110.002980.

25. Bunt SK, Sinha P, Clements VK, Leips J, Ostrand-Rosenberg S. Inflammation induces myeloid-derived suppressor cells that facilitate tumor progression. J Immunol. 2006; 176: 284-90.

26. Taylor DD, Gercel-Taylor C. Exosomes/microvesicles: mediators of cancer-associated immunosuppressive microenvironments. Semin Immunopathol. 2011; 33: 441-54.

27. Panopoulos AD, Watowich SS. Granulocyte colony-stimulating factor: molecular mechanisms of action during steady state and 'emergency' hematopoiesis. Cytokine. 2008; 42: 277-88.

28. Touw IP, van de Geijn GJ. Granulocyte colony-stimulating factor and its receptor in normal myeloid cell development, leukemia and related blood cell disorders. Front Biosci. 2007; 12: 800-15.

29. Barreda DR, Hanington PC, Belosevic M. Regulation of myeloid development and function by colony stimulating factors. Dev Comp Immunol. 2004; 28: 509-54.

30. Revoltella RP, Menicagli M, Campani D. Granulocyte-macrophage colony-stimulating factor as an autocrine survival-growth factor in human gliomas. Cytokine. 2012; 57: 347-59.

31. Maione P, Rossi A, Di Maio M, Gridelli C. Tumor-related leucocytosis and chemotherapy-induced neutropenia: linked or independent prognostic factors for advanced non-small cell lung cancer? Lung Cancer. 2009; 66: 8-14

32. Morales JK, Kmieciak M, Knutson KL, Bear HD, Manjili MH. GM-CSF is one of the main breast tumor-derived soluble factors involved in the differentiation of CD11b-Gr1- bone marrow progenitor cells into myeloid-derived suppressor cells. Breast Cancer Res Treat. 2010; 123: 39-49.

33. Dolcetti L, Peranzoni E, Ugel S, et al. Hierarchy of immunosuppressive strength among myeloid-derived suppressor cell subsets is determined by GM-CSF. Eur J Immunol. 2010; 40: 22-35.

34. Lutz MB, Suri RM, Niimi M, et al. Immature dendritic cells generated with low doses of GM-CSF in the absence of IL-4 are maturation resistant and prolong allograft survival in vivo. Eur J Immunol. 2000; 30: 1813-22.

35. Ribechini E, Greifenberg V, Sandwick S, Lutz MB. Subsets, expansion and activation of myeloid-derived suppressor cells. Med Microbiol Immunol. 2010; 199: 273-81.

36. Lechner MG, Liebertz DJ, Epstein AL. Characterization of cytokine-induced myeloid-derived suppressor cells from normal human peripheral blood mononuclear cells. J Immunol. 2010; 185: 2273-84.

37. Gerber HP, Ferrara N. The role of VEGF in normal and neoplastic hematopoiesis. J Mol Med (Berl). 2003; 81: 20-31.

38. Casella I, Feccia T, Chelucci C, et al. Autocrine-paracrine VEGF loops potentiate the maturation of megakaryocytic precursors through Flt1 receptor. Blood. 2003; 101: 1316-23.

39. Söderberg SS, Karlsson G, Karlsson S. Complex and context dependent regulation of hematopoiesis by TGF-beta superfamily signaling. Ann N Y Acad Sci. 2009; 1176: 55-69.

40. Johnson B, Osada T, Clay T, Lyerly H, Morse M. Physiology and therapeutics of vascular endothelial growth factor in tumor immunosuppression. Curr Mol Med. 2009; 9: 702-7.

41. Ohm JE, Carbone DP. VEGF as a mediator of tumor-associated immunodeficiency. Immunol Res. 2001; 23: 263-72.

42. Flavell RA, Sanjabi S, Wrzesinski SH, Licona-Limón P. The polarization of immune cells in the tumour environment by TGFbeta. Nat Rev Immunol. 2010; 10: 554-67.

43. Kim R, Emi M, Tanabe K. Cancer cell immune escape and tumor progression by exploitation of anti-inflammatory and pro-inflammatory responses. Cancer Biol Ther. 2005; 4: 924-33. 
44. Majka M, Janowska-Wieczorek A, Ratajczak J, et al. Numerous growth factors, cytokines, and chemokines are secreted by human CD34(+) cells, myeloblasts, erythroblasts, and megakaryoblasts and regulate normal hematopoiesis in an autocrine/paracrine manner. Blood. 2001; 97: 3075-85.

45. Travlos G. Normal structure, function, and histology of the bone marrow. Toxicol Pathol. 2006; 34: 548-65.

46. Apte RN, Voronov E. Is interleukin-1 a good or bad 'guy' in tumor immunobiology and immunotherapy? Immunol Rev. 2008; 222: 222-41.

47. Elkabets M, Ribeiro VS, Dinarello CA, et al. IL-1 $\beta$ regulates a novel myeloid-derived suppressor cell subset that impairs NK cell development and function. Eur J Immunol. 2010; 40: 3347-57.

48. Bunt SK, Clements VK, Hanson EM, Sinha P, Ostrand-Rosenberg S. Inflammation enhances myeloid-derived suppressor cell cross-talk by signaling through Toll-like receptor 4. J Leukoc Biol. 2009; 85: 996-1004.

49. Tu S, Bhagat G, Cui G, et al. Overexpression of interleukin-1beta induces gastric inflammation and cancer and mobilizes myeloid-derived suppressor cells in mice. Cancer Cell. 2008; 14: 408-19.

50. Kao AP, Wang KH, Long $\mathrm{CY}$, et al. Interleukin- $1 \beta$ induces cyclooxygenase- 2 expression and promotes the invasive ability of human mesenchymal stem cells derived from ovarian endometrioma. Fertil Steril. 2011; 96: 678-84.e1.

51. Eruslanov E, Daurkin I, Ortiz J, Vieweg J, Kusmartsev S. Pivotal Advance: Tumor-mediated induction of myeloid-derived suppressor cells and M2-polarized macrophages by altering intracellular $\mathrm{PGE}_{2}$ catabolism in myeloid cells. J Leukoc Biol. 2010; 88: 39-48

52. Sinha P, Clements VK, Fulton AM, Ostrand-Rosenberg S. Prostaglandin E2 promotes tumor progression by inducing myeloid-derived suppressor cells. Cancer Res. 2007; 67: 4507-13.

53. Ledesma E, Martvnez I, Cordova Y, et al. Interleukin-1 beta (IL-1beta) induces tumor necrosis factor alpha (TNF-alpha) expression on mouse myeloid multipotent cell line 32D $\mathrm{cl} 3$ and inhibits their proliferation. Cytokine. 2004; 26: 66-72.

54. Larysz-Brysz M, Lewin-Kowalik J, Czuba Z, et al. Interleukin-1 $\beta$ Increases Release of Endothelin-1 and Tumor Necrosis Factor As Well As Reactive Oxygen Species by Peripheral Leukocytes during Experimental Subarachnoid Hemorrhage. Curr Neurovasc Res. 2012; Epub ahead of print.

55. Park EJ, Kwon TK. Rottlerin enhances IL-1 $\beta$-induced COX-2 expression through sustained p38 MAPK activation in MDA-MB-231 human breast cancer cells. Exp Mol Med. 2011; 43: 669-75.

56. Hanson EM, Clements VK, Sinha P, Ilkovitch D, Ostrand-Rosenberg S. Myeloid-derived suppressor cells down-regulate L-selectin expression on CD4+ and CD8+ T cells. J Immunol. 2009; 183: 937-44.

57. Soria G, Ofri-Shahak M, Haas I, et al. Inflammatory mediators in breast cancer: coordinated expression of TNFa \& IL-1 $\beta$ with CCL2 \& CCL5 and effects on epithelial-to-mesenchymal transition. BMC Cancer. 2011; 11: 130.

58. Greifenberg V, Ribechini E, Rössner S, Lutz MB. Myeloid-derived suppressor cell activation by combined LPS and IFN-gamma treatment impairs DC development. Eur J Immunol. 2009; 39: 2865-76.

59. Boneberg EM, Hartung T. Febrile temperatures attenuate IL-1 beta release by inhibiting proteolytic processing of the proform and influence Th1/Th2 balance by favoring Th2 cytokines. J Immunol. 2003; 171: 664-8.

60. Stathopoulos GT, Sherrill TP, Karabela SP, et al. Host-derived interleukin-5 promotes adenocarcinoma-induced malignant pleural effusion. Am J Respir Crit Care Med. 2010; 182: 1273-81.

61. Gabitass RF, Annels NE, Stocken DD, Pandha HA, Middleton GW. Elevated myeloid-derived suppressor cells in pancreatic, esophageal and gastric cancer are an independent prognostic factor and are associated with significant elevation of the Th2 cytokine interleukin-13. Cancer Immunol Immunother. 2011; 60: 1419-30.

62. Neurath MF, Finotto S. IL-6 signaling in autoimmunity, chronic inflammation and inflammation-associated cancer. Cytokine Growth Factor Rev. 2011; 22: 83-9.

63. Scheller J, Ohnesorge N, Rose-John S. Interleukin-6 trans-signalling in chronic inflammation and cancer. Scand J Immunol. 2006; 63: 321-9.

64. Mundy-Bosse BL, Young GS, Bauer T, et al. Distinct myeloid suppressor cell subsets correlate with plasma IL-6 and IL-10 and reduced interferon-alpha signaling in $\mathrm{CD}^{+} \mathrm{T}$ cells from patients with GI malignancy. Cancer Immunol Immunother. 2011; 60: 1269-79.

65. Wu CT, Hsieh CC, Lin CC, Chen WC, Hong JH, Chen MF. Significance of IL-6 in the transition of hormone-resistant prostate cancer and the induction of myeloid-derived suppressor cells. J Mol Med (Berl). 2012; DOI:10.1007/s00109-012-0916-x.
66. Cheng L, Wang J, Li X, et al. Interleukin-6 induces Gr-1+CD11b+ myeloid cells to suppress CD8+ T cell-mediated liver injury in mice. PLoS One. 2011; 6: e17631.

67. Wu L, Du H, Li Y, Qu P, Yan C. Signal transducer and activator of transcription 3 (Stat3C) promotes myeloid-derived suppressor cell expansion and immune suppression during lung tumorigenesis. Am J Pathol. 2011; 179: 2131-41.

68. Chalmin F, Ladoire S, Mignot G, et al. Membrane-associated Hsp72 from tumor-derived exosomes mediates STAT3-dependent immunosuppressive function of mouse and human myeloid-derived suppressor cells. J Clin Invest. 2010; 120: 457-71.

69. Sonda N, Chioda M, Zilio S, Simonato F, Bronte V. Transcription factors in myeloid-derived suppressor cell recruitment and function. Curr Opin Immunol. 2011; 23: 279-85.

70. Sumida K, Wakita D, Narita Y, et al. Anti-IL-6 receptor mAb eliminates myeloid-derived suppressor cells and inhibits tumor growth by enhancing T-cell responses. Eur J Immunol. 2012; 42: 2060-72.

71. Lesokhin AM, Hohl TM, Kitano S, et al. Monocytic CCR2(+) myeloid-derived suppressor cells promote immune escape by limiting activated CD8 T-cell infiltration into the tumor microenvironment. Cancer Res. 2012; 72: 876-86.

72. Zhang J, Patel L, Pienta KJ. CC chemokine ligand 2 (CCL2) promotes prostate cancer tumorigenesis and metastasis. Cytokine Growth Factor Rev. 2010; 21: 41-8.

73. Iwata Y, Furuichi K, Kitagawa K, et al. Involvement of CD11b+ GR-1 low cells in autoimmune disorder in MRL-Fas lpr mouse. Clin Exp Nephrol. 2010; 14: 411-7.

74. Zollo M, Di Dato V, Spano D, et al. Targeting monocyte chemotactic protein-1 synthesis with bindarit induces tumor regression in prostate and breast cancer animal models. Clin Exp Metastasis 2012; 29: 585-601.

75. Takehara H, Iwamoto J, Mizokami Y, et al. Involvement of cyclooxygenase-2--prostaglandin E2 pathway in interleukin-8 production in gastric cancer cells. Dig Dis Sci. 2006; 51: 2188-97.

76. Obermajer N, Muthuswamy R, Odunsi K, Edwards RP, Kalinski P. PGE(2)-induced CXCL12 production and CXCR4 expression controls the accumulation of human MDSCs in ovarian cancer environment. Cancer Res. 2011; 71: 7463-70.

77. Kalinski P. Regulation of immune responses by prostaglandin E2. J Immunol. 2012; 188: 21-8.

78. Williams SA, Harata-Lee Y, Comerford I, Anderson RL, Smyth MJ, McColl SR. Multiple functions of CXCL12 in a syngeneic model of breast cancer. Mol Cancer. 2010; 9: 250.

79. Gama L, Shirk EN, Russell JN, et al. Expansion of a subset of CD14highCD16negCCR2low/neg monocytes functionally similar to myeloid-derived suppressor cells during SIV and HIV infection. J Leukoc Biol. 2012; 91: 803-16.

80. Connolly MK, Mallen-St Clair J, Bedrosian AS, et al. Distinct populations of metastases-enabling myeloid cells expand in the liver of mice harboring invasive and preinvasive intra-abdominal tumor. J Leukoc Biol. 2010; 87: 713-25.

81. Ichikawa M, Williams R, Wang L, Vogl T, Srikrishna G. S100A8/A9 activate key genes and pathways in colon tumor progression. Mol Cancer Res. 2011; 9: 133-48.

82. Sawanobori $\mathrm{Y}$, Ueha $\mathrm{S}$, Kurachi $\mathrm{M}$, et al. Chemokine-mediated rapid turnover of myeloid-derived suppressor cells in tumor-bearing mice. Blood. 2008; 111: 5457-66.

83. Qu P, Du H, Li Y, Yan C. Myeloid-specific expression of Api6/AIM/Sp alpha induces systemic inflammation and adenocarcinoma in the lung. $J$ Immunol. 2009; 182: 1648-59.

84. Bian Y, Hall B, Sun ZJ, et al. Loss of TGF- $\beta$ signaling and PTEN promotes head and neck squamous cell carcinoma through cellular senescence evasion and cancer-related inflammation. Oncogene 2012; 31: 3322-32.

85. Ye XZ, Yu SC, Bian XW. Contribution of myeloid-derived suppressor cells to tumor-induced immune suppression, angiogenesis, invasion and metastasis. J Genet Genomics. 2010; 37: 423-30.

86. Park SI, Soki FN, McCauley LK. Roles of bone marrow cells in skeletal metastases: no longer bystanders. Cancer Microenviron. 2011; 4: 237-46.

87. Hermani A, De Servi B, Medunjanin S, Tessier PA, Mayer D. S100A8 and S100A9 activate MAP kinase and NF-kappaB signaling pathways and trigger translocation of RAGE in human prostate cancer cells. Exp Cell Res. 2006; 312: 184-97.

88. Sinha P, Okoro C, Foell D, Freeze HH, Ostrand-Rosenberg S, Srikrishna G. Proinflammatory S100 proteins regulate the accumulation of myeloid-derived suppressor cells. J Immunol. 2008; 181: 4666-75.

89. Turovskaya O, Foell D, Sinha P, et al. RAGE, carboxylated glycans and S100A8/A9 play essential roles in colitis-associated carcinogenesis. Carcinogenesis. 2008; 29: 2035-43. 
90. Nagaraj S, Schrum AG, Cho HI, Celis E, Gabrilovich DI. Mechanism of T cell tolerance induced by myeloid-derived suppressor cells. J Immunol. 2010; 184: 3106-16.

91. Kao J, Ko EC, Eisenstein S, Sikora AG, Fu S, Chen SH. Targeting immune suppressing myeloid-derived suppressor cells in oncology. Crit Rev Oncol Hematol. 2011; 77: 12-9.

92. Montero AJ, Diaz-Montero CM, Kyriakopoulos CE, Bronte V, Mandruzzato S. Myeloid-derived suppressor cells in cancer patients: a clinical perspective. J Immunother. 2012; 35: 107-15.

93. Pan PY, Wang GX, Yin B, et al. Reversion of immune tolerance in advanced malignancy: modulation of myeloid-derived suppressor cell development by blockade of stem-cell factor function. Blood. 2008; 111: 219-28.

94. Kumar R, Crouthamel MC, Rominger DH, et al. Myelosuppression and kinase selectivity of multikinase angiogenesis inhibitors. Br J Cancer. 2009; 101: 1717-23.

95. Ozao-Choy J, Ma G, Kao J, et al. The novel role of tyrosine kinase inhibitor in the reversal of immune suppression and modulation of tumor microenvironment for immune-based cancer therapies. Cancer Res. 2009; 69: 2514-22.

96. Ko JS, Zea AH, Rini BI, et al. Sunitinib mediates reversal of myeloid-derived suppressor cell accumulation in renal cell carcinoma patients. Clin Cancer Res. 2009; 15: 2148-57.

97. Ko JS, Rayman P, Ireland J, et al. Direct and differential suppression of myeloid-derived suppressor cell subsets by sunitinib is compartmentally constrained. Cancer Res. 2010; 70: 3526-36.

98. Porta C, Paglino C, Imarisio I, Ganini C, Pedrazzoli P. Immunological effects of multikinase inhibitors for kidney cancer: a clue for integration with cellular therapies? J Cancer. 2011; 2: 333-8.

99. Mirza N, Fishman M, Fricke I, et al. All-trans-retinoic acid improves differentiation of myeloid cells and immune response in cancer patients. Cancer Res. 2006; 66: 9299-307.

100. Song X, Ye D, Liu B, et al. Combination of all-trans retinoic acid and a human papillomavirus therapeutic vaccine suppresses the number and function of immature myeloid cells and enhances antitumor immunity. Cancer Sci. 2009; 100: 334-40.

101. Michels T, Shurin GV, Naiditch H, Sevko A, Umansky V, Shurin MR. Paclitaxel promotes differentiation of myeloid-derived suppressor cells into dendritic cells in vitro in a TLR4-independent manner. J Immunotoxicol 2012; 9: 292-300.

102. Friedman A. Transcriptional control of granulocyte and monocyte development. Oncogene. 2007; 26: 6816-28.

103. Collins S. The role of retinoids and retinoic acid receptors in normal hematopoiesis. Leukemia. 2002; 16: 1896-905.

104. Shurin MR, Naiditch H, Gutkin DW, Umansky V, Shurin GV. ChemoImmunoModulation: immune regulation by the antineoplastic chemotherapeutic agents. Curr Med Chem. 2012; 19: 1792-803.

105. Sevko A, Kremer V, Falk C, et al. Application of paclitaxel in low non-cytotoxic doses supports vaccination with melanoma antigens in normal mice. J Immunotoxicol 2012; 9: 275-81.

106. Suzuki E, Kapoor V, Jassar AS, Kaiser LR, Albelda SM. Gemcitabine selectively eliminates splenic Gr-1+/CD11b+ myeloid suppressor cells in tumor-bearing animals and enhances antitumor immune activity. Clin Cancer Res. 2005; 11: 6713-21.

107. Le HK, Graham L, Cha E, Morales JK, Manjili MH, Bear HD. Gemcitabine directly inhibits myeloid derived suppressor cells in BALB/c mice bearing 4T1 mammary carcinoma and augments expansion of $\mathrm{T}$ cells from tumor-bearing mice. Int Immunopharmacol. 2009; 9: 900-9.

108. Vincent J, Mignot G, Chalmin F, et al. 5-Fluorouracil selectively kills tumor-associated myeloid-derived suppressor cells resulting in enhanced T cell-dependent antitumor immunity. Cancer Res. 2010; 70: 3052-61.

109. Kimpfler S, Sevko A, Ring S, et al. Skin melanoma development in ret transgenic mice despite the depletion of CD25+Foxp3+ regulatory T cells in lymphoid organs. J Immunol. 2009; 183: 6330-7.

110. Boelte KC, Gordy LE, Joyce S, Thompson MA, Yang L, Lin PC. Rgs2 mediates pro-angiogenic function of myeloid derived suppressor cells in the tumor microenvironment via upregulation of MCP-1. PLoS One. 2011; 6: e18534.

111. Arabzadeh A, Chan C, Nouvion AL, et al. Host-related carcinoembryonic antigen cell adhesion molecule 1 promotes metastasis of colorectal cancer. Oncogene. 2012; doi: 10.1038/onc.2012.112.

112. Umansky V, Schirrmacher V. Nitric oxide-induced apoptosis in tumor cells. Adv Cancer Res. 2001; 82: 107-31.

113. Bronte V, Zanovello P. Regulation of immune responses by L-arginine metabolism. Nat Rev Immunol. 2005; 5: 641-54.
114. Ghofrani HA, Osterloh IH, Grimminger F. Sildenafil from angina to erectile dysfunction to pulmonary hypertension and beyond. Nat Rev Drug Discov. 2006; 5: 689-702.

115. Capuano G, Rigamonti N, Grioni M, Freschi M, Bellone M. Modulators of arginine metabolism support cancer immunosurveillance. BMC Immunol. 2009; 10: 1.

116. Serafini P, Meckel K, Kelso M, et al. Phosphodiesterase-5 inhibition augments endogenous antitumor immunity by reducing myeloid-derived suppressor cell function. J Exp Med. 2006; 203: 2691-702.

117. Ugel S, Delpozzo F, Desantis G, et al. Therapeutic targeting of myeloid-derived suppressor cells. Curr Opin Pharmacol. 2009; 9: 470-81.

118. Jayaraman P, Parikh F, Lopez-Rivera E, et al. Tumor-Expressed Inducible Nitric Oxide Synthase Controls Induction of Functional Myeloid-Derived Suppressor Cells through Modulation of Vascular Endothelial Growth Factor Release. J Immunol. 2012; 188: 5365-76.

119. De Santo C, Serafini P, Marigo I, et al. Nitroaspirin corrects immune dysfunction in tumor-bearing hosts and promotes tumor eradication by cancer vaccination. Proc Natl Acad Sci U S A. 2005; 102: 4185-90.

120. Veltman JD, Lambers ME, van Nimwegen $M$, et al. COX-2 inhibition improves immunotherapy and is associated with decreased numbers of myeloid-derived suppressor cells in mesothelioma. Celecoxib influences MDSC function. BMC Cancer. 2010; 10: 464.

121. Fujita M, Kohanbash G, Fellows-Mayle W, et al. COX-2 blockade suppresses gliomagenesis by inhibiting myeloid-derived suppressor cells. Cancer Res. 2011; 71: 2664-74.

122. Ochoa AC, Zea A, Hernandez C, Rodriguez PC. Arginase, prostaglandins, and myeloid-derived suppressor cells in renal cell carcinoma. Clin Cancer Res. 2007; 13(2 Pt 2): 721s-6s. 